\title{
New potent and selective polyfluoroalkyl ketone inhibitors of GVIA calcium-independent phospholipase $A_{2}$
}

\author{
Victoria Magrioti ${ }^{\mathrm{a}}$, Aikaterini Nikolaou ${ }^{\mathrm{a}}$, Annetta Smyrniotou ${ }^{\mathrm{b}}$, Ishita Shah ${ }^{\mathrm{c}, \mathrm{d}}$, \\ Violetta Constantinou-Kokotou $^{b}$, Edward A. Dennis ${ }^{\mathrm{c}, \mathrm{d}, *}$, George Kokotos ${ }^{\mathrm{a}, *}$ \\ a Laboratory of Organic Chemistry, Department of Chemistry, University of Athens, Panepistimiopolis, Athens 15771, Greece \\ ${ }^{\mathrm{b}}$ Chemical Laboratories, Agricultural University of Athens, Athens 11855, Greece \\ ' Department of Chemistry and Biochemistry, School of Medicine, MC 0601, University of California, San Diego, La Jolla, CA 92093-0601, USA \\ ${ }^{\mathrm{d}}$ Department of Pharmacology, School of Medicine, MC 0601, University of California, San Diego, La Jolla, CA 92093-0601, USA
}

\section{A R T I C L E I N F O}

\section{Article history:}

Received 17 May 2013

Accepted 6 July 2013

Available online 16 July 2013

\section{Keywords:}

Phospholipase $\mathrm{A}_{2}$

Inhibitor

GVIA iPLA

Polyfluoroalkyl ketone

Pentafluoroethyl ketones

\begin{abstract}
A B S T R A C T
Group VIA calcium-independent phospholipase $A_{2}\left(G V I A\right.$ iPLA $\left.A_{2}\right)$ has recently emerged as an important pharmaceutical target. Selective and potent GVIA iPLA $A_{2}$ inhibitors can be used to study its role in various neurological disorders. In the current work, we explore the significance of the introduction of a substituent in previously reported potent GVIA iPLA ${ }_{2}$ inhibitors. 1,1,1,2,2-Pentafluoro-7-(4-methoxyphenyl)heptan-3-one (GK187) is the most potent and selective GVIA iPLA $A_{2}$ inhibitor ever reported with a $X_{\mathrm{I}}(50)$ value of 0.0001 , and with no significant inhibition against GIVA cPLA ${ }_{2}$ or GV sPLA 2 . We also compare the inhibition of two difluoromethyl ketones on GVIA iPLA , GIVA CPLA $_{2}$, and GV SPLA 2 .
\end{abstract}

(c) 2013 Elsevier Ltd. All rights reserved.

\section{Introduction}

Phospholipases $\mathrm{A}_{2}$ are the enzymes that hydrolyse the ester bond of phospholipids at the $s n-2$ position releasing free fatty acids and lysophospholipids. ${ }^{1}$ Both of the products of this hydrolysis may generate second messengers that play significant pharmacological roles, and especially when the released free fatty acid is arachidonic acid. The $\mathrm{PLA}_{2}$ superfamily currently consists of 16 different groups and various subgroups. ${ }^{2}$ Three of the most important types of $\mathrm{PLA}_{2} \mathrm{~S}$ that can be found in human tissues are the secreted (such as GIIA and GV SPLA $A_{2}$ ), the cytosolic GIVA CPLA 2 and the calcium-independent GVIA iPLA 2 .

GIVA $\mathrm{CPA}_{2}$ is considered to be a proinflammatory enzyme that is the rate-limiting provider of arachidonic acid and lysophospholipids. ${ }^{3}$ GIVA cPLA 2 is regulated by intracellular calcium, and calcium binding to the $\mathrm{C} 2$ domain of GIVA PLA 2 can activate the enzyme, resulting in the localization of the enzyme to the phospholipid membrane. ${ }^{4,5}$ Furthermore, the activity of $\mathrm{SPLA}_{2} \mathrm{~S}$ has been suggested to be dependent on or linked to the activity of $\mathrm{CPLA}_{2}{ }^{6-8}$

* Corresponding authors. Tel.: +1 858534 3055; fax: +1 8585347390 (E.A.D.); tel.: +30 210727 4462; fax: +30 2107274761 (G.K.).

E-mail addresses: edennis@ucsd.edu (E.A. Dennis), gkokotos@chem.uoa.gr (G. Kokotos).
GVIA iPLA $A_{2}$ is a phospholipase $A_{2}$ that can be characterized by its calcium-independent activity. It was purified and characterized from macrophages in $1994^{9}$ and it functions through a catalytic serine at the active site in a patatin-like $\alpha / \beta$-hydrolase domain. It is a 752-amino acid protein with a molecular mass of $85 \mathrm{kDa}$ that contains eight ankyrin repeats and a catalytic domain. ${ }^{10-12}$ Both intracellular enzymes GIVA CPLA 2 and GVIA iPLA ${ }_{2}$ share the same catalytic mechanism utilizing a serine residue as the nucleophile,

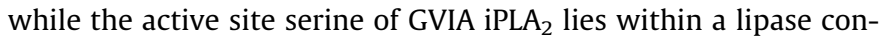
sensus sequence (Gly-X-Ser519-X-Gly) on top of the catalytic domain. ${ }^{2}$ GVIA iPLA 2 is known to be a homeostatic enzyme involved in basal metabolism within the cell. ${ }^{13-19}$ Several studies also suggest that GVIA iPLA ${ }_{2}$ plays significant roles in numerous cell types, although they may differ from cell to cell. Recent review articles discuss the role of GVIA iPLA ${ }_{2}$ in signaling and pathological conditions (e.g., diabetes, Barth syndrome, ischemia and cancer). ${ }^{20-27}$

Various GVIA iPLA 2 inhibitor classes have been discussed in recent review articles. ${ }^{2,28-30}$ The first reported GVIA iPLA ${ }_{2}$ inhibitors were the trifluoromethyl ketones, ${ }^{31}$ tricarbonyls ${ }^{32}$ and methyl fluorophosphonates $^{33}$ of fatty acids, such as arachidonic acid. They were not very potent, nor selective inhibitors, while the methyl fluorophosphonates were also irreversible. Most recently, cardiolipin was found to inhibit iPLA $_{2}$ and CPLA $_{2}$ activity towards PC in vitro. ${ }^{34}$

Bromoenol lactone (BEL, Fig. 1) was considered to be a selective, irreversible GVIA iPLA 2 inhibitor and was used to study potential 


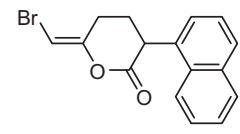

BEL

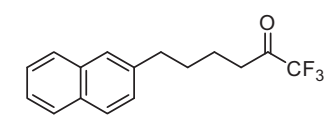

FKGK18

Figure 1. Some known iPLA 2 inhibitors.

biological functions of GVIA iPLA $2 \cdot{ }^{13,31}$ The inactivation mechanism of GVIA iPLA 2 by BEL has been studied by Turk and co-workers. ${ }^{35}$ It is likely that this inhibitor affects multiple enzymes and should be used with appropriate caution when studying potential roles of GVIA iPLA 2 .

The development of selective inhibitors for the three main human $\mathrm{PLA}_{2}$ enzymes is of paramount importance. Our groups have previously synthesized and assayed a series of polyfluoroalkyl ketones for their activity on GIVA cPLA 2 , GVIA iPLA, and GVs$\mathrm{PLA}_{2}{ }^{36,37}$ When compared to a trifluoromethyl ketone, it was found that the corresponding pentafluoroethyl ketone favored selective GVIA iPLA ${ }_{2}$ inhibition. FKGK11 (Fig. 1) was found to be a selective GVIA iPLA 2 inhibitor, while FKGK18 (Fig. 1) was identified as the most potent GVIA PLA ${ }_{2}$ inhibitor yet reported. ${ }^{37}$ Selective $\mathrm{PLA}_{2}$ inhibitors may contribute to the clarification of the role of each PLA $\mathrm{P}_{2}$ class in various disorders. Using the selective GVIA iPLA $_{2}$ inhibitor FKGK11, a selective GIVA CPLA $A_{2}$ inhibitor, and a pan-PLA $A_{2}$ inhibitor, the role of the various classes of PLA $\mathrm{A}_{2}$ in an animal model of multiple sclerosis, EAE, was studied. ${ }^{38}$ According to the results of that study, GIVA CPLA 2 plays a role in the onset of the disease, while GVIA iPLA ${ }_{2}$ plays a key role in both the onset and the progression of the disease. Therefore, it appears that GVIA $\mathrm{iPLA}_{2}$ is a target enzyme for the development of novel therapies for multiple sclerosis. ${ }^{38}$ Furthermore, in a very recent article, the inhi-

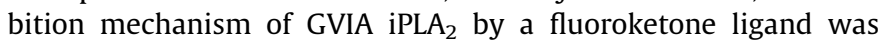
examined using a combination of deuterium exchange mass spectrometry (DXMS) and molecular dynamics (MD), while models for iPLA $_{2}$ were built by homology with the known structure of patatin. ${ }^{39}$ The discovery of the precise binding mode of fluoroketone ligands to $\mathrm{iPLA}_{2}$ should greatly improve our ability to design new inhibitors with higher potency and selectivity.

Based on previous results, we have explored further this family of GVIA iPLA 2 inhibitors and herein we describe our most recent results.

\section{Results and discussion}

\subsection{Design of inhibitors}

The design of the novel polyfluoroalkyl ketones was based on the optimization of the activity and selectivity of iPLA $_{2}$ inhibitors that we have presented in previous work, such as FKGK11 and FKGK18 (Fig. 1). ${ }^{36,37}$ Having established that the best linker between a polyfluoroalkyl ketone and an aromatic ring is a chain of four methylene groups, we introduced in the aromatic ring different substituents and studied the effect of these substituents on the affinity towards GVIA iPLA 2 , as well as the selectivity towards GVIA iPLA $_{2}$ when compared to GIVA cPLA ${ }_{2}$ and GV sPLA 2 activity. Several substituents were introduced in para position, such as a fluorine atom, a methoxy group, a phenyl group, and a trifluoromethyl group. Also, the isomer of the most potent iPLA 2 inhibitor FKGK18 was prepared, where the naphthyl group was attached to the linker at the 1-position.
Furthermore, compounds $\mathbf{1 2}$ and $\mathbf{1 3}$ were synthesized as the structurally restricted analogues of the inhibitor FKGK11 to determine the effect that the second phenyl group would have on the activity of the inhibitor.

Finally, two difluoromethyl ketones were prepared that resembled the structure of inhibitor FKGK11 in order to identify the effect that different number of fluorine atoms would have on the activity of polyfluoroalkyl ketones.

The inhibition studies showed high activity and selectivity for compounds $\mathbf{5 d}$ and $\mathbf{6 d}$ that had a methoxy group at para position. Thus, we prepared another series of substituted polyfluoroalkyl ketones bearing one or two methoxy groups in different positions of the phenyl or in the naphthalene group to see the effect on inhibition and selectivity.

\subsection{Synthesis of inhibitors}

For the synthesis of trifluomethyl and pentafluoroethyl ketones $\mathbf{5 a}-\mathbf{j}$ and $\mathbf{6 a}-\mathbf{j}$, a Wadsworth-Horner-Emmons olefination reaction of the corresponding commercially available substituted aromatic aldehydes $1 \mathbf{a}-\mathbf{j}$ with triethyl phosphonocrotonate yielded the usaturated esters $\mathbf{2 a}-\mathbf{j}$ (Scheme 1). Hydrogenation with $10 \% \mathrm{Pd} / \mathrm{C}$ gave esters $\mathbf{3 a}-\mathbf{j}$, followed by saponification to afford acids $\mathbf{4 a - j}$.

After treating compounds $\mathbf{4 a}-\mathbf{j}$ with oxalyl chloride, the corresponding chlorides were treated with trifluoroacetic or pentafluoropropionic anhydride and pyridine to yield trifluoromethyl ketones $5 \mathbf{a}-\mathbf{j}$ and pentafluoropropyl ketones $\mathbf{6 a}-\mathbf{j}$. In the case of heptafluorobutyl ketone $\mathbf{7 a}$, the corresponding chloride was treated with heptafluorobutyric anhydride and pyridine.
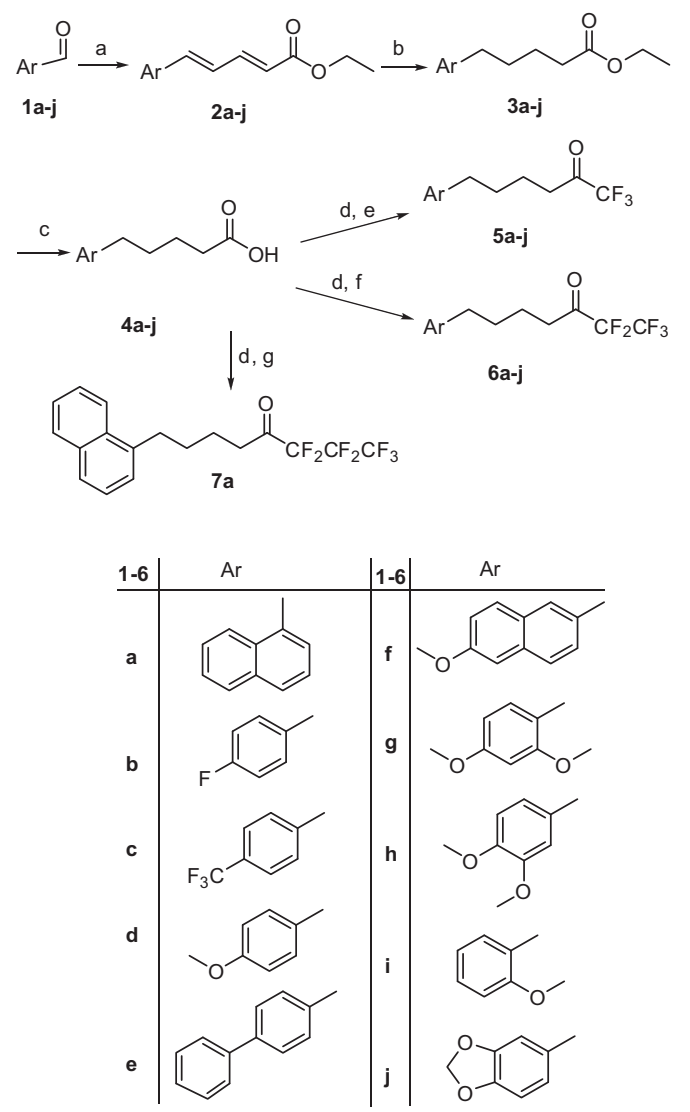

Scheme 1. Reagents and conditions: (a) $\mathrm{C}_{2} \mathrm{H}_{5} \mathrm{OOCCH}=\mathrm{CHCH}_{2} \mathrm{P}(=\mathrm{O})\left(\mathrm{OC}_{2} \mathrm{H}_{5}\right)_{2}$, $\mathrm{LiOH}$, THF, reflux; (b) $\mathrm{H}_{2}, 10 \% \mathrm{Pd} / \mathrm{C}$, EtOH; (c) $\mathrm{NaOH} 1 \mathrm{~N}$, EtOH; (d) $(\mathrm{COCl})_{2}, \mathrm{DMF}, \mathrm{CH}_{2} \mathrm{Cl}_{2}$; (e) pyridine, $\left(\mathrm{CF}_{3} \mathrm{CO}\right)_{2} \mathrm{O}, \mathrm{CH}_{2} \mathrm{Cl}_{2}, 0{ }^{\circ} \mathrm{C}$ to rt; (f) pyridine, $\left(\mathrm{CF}_{3} \mathrm{CF}_{2} \mathrm{CO}\right)_{2} \mathrm{O}, \mathrm{CH}_{2} \mathrm{Cl}_{2}, 0^{\circ} \mathrm{C}$ to rt; (g) pyridine, $\left(\mathrm{CF}_{3} \mathrm{CF}_{2} \mathrm{CF}_{2} \mathrm{CO}\right)_{2} \mathrm{O}, \mathrm{CH}_{2} \mathrm{Cl}_{2}, \mathrm{O}^{\circ} \mathrm{C}$ to rt. 
For the synthesis of trifluomethyl and pentafluoroethyl ketones 12 and 13, a Wittig olefination reaction between aldehyde 8 and methyl (triphenylphosphanylidene)acetate yielded usaturated ester 9 (Scheme 2). Catalytic hydrogenation, followed by saponification gave compound 11. Ketones 12 and 13 were prepared similarly as described above.

The difluoromethyl ketones were prepared from bromides 14a and $\mathbf{1 4 b}$, after being treated with magnesium, and the corresponding Grignard reagents were slowly added to ethyl difluoroacetate at $-78{ }^{\circ} \mathrm{C}$ to yield ketones $\mathbf{1 6} \mathbf{a}$ and $\mathbf{1 6 b}$ (Scheme 3 ).

\subsection{In vitro inhibition of GIIA SPLA ${ }_{2}$, GIVA $_{\text {CPLA }}$ and GVIA iPLA}

All synthesized inhibitors were tested for inhibition of human GIVA cPLA $A_{2}$, GVIA iPLA ind $_{2}$ and sPLA $_{2}$ using previously described mixed micelle-based assays. ${ }^{40-42}$ The inhibition results are presented in Table 1, either as percent inhibition or as $X_{\mathrm{I}}(50)$ values. At first, the percent of inhibition for each $\mathrm{PLA}_{2}$ enzyme at 0.091 mole fraction of each inhibitor was determined; and, then the $X_{\mathrm{I}}(50)$ values were measured for compounds that displayed greater than $95 \%$ inhibition. The $X_{\mathrm{I}}(50)$ is the mole fraction of the inhibitor in the total substrate interface required to inhibit the enzyme by $50 \%$.

The isomer of the most potent iPLA 2 inhibitor FKGK18, compound 5a seems to be a 9-times weaker inhibitor towards GVIA iPLA $_{2}$, while there is no significant selectivity towards GIVA CPLA 2 . Interestingly enough, the pentafluoro and heptafluoro ketone analogues $\mathbf{6 a}$ and $7 \mathbf{a}$ are even weaker iPLA ${ }_{2}$ inhibitors. The methoxy group in position 6 of the naphthalene group also seems to lower the inhibitory potency of FKGK18 in compounds $\mathbf{5 f}$ and $\mathbf{6 f}$.

Compounds $\mathbf{5 b}-\mathbf{e}$ and $\mathbf{6 b}-\mathbf{e}$ were prepared as substituted analogues of FKGK11. Most of these compounds presented excellent iPLA $_{2}$ inhibition, with the exception of compounds $\mathbf{5 e}$ and $\mathbf{6 e}$, which were 13 -fold and ninefold weaker towards iPLA $_{2}$ than FKGK11. It was interesting though that trifluoromethyl ketone 5e, 6-(biphenyl-4-yl)-1,1,1-trifluorohexan-2-one (GK174), seemed to be a more potent inhibitor towards GIVA CPLA 2 than for GVIA iPLA $_{2}$. Compounds 5b (GK176) and 5c (GK178) proved to be as potent as FKGK18, and compound $\mathbf{5 c}$ showed even better selectivity

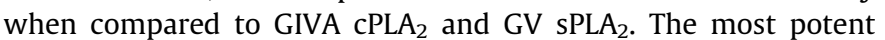
inhibitors proved to be compounds 5d (1,1,1-trifluoro-6-(4methoxyphenyl)hexan-2-one, GK177) and 6d (1,1,1,2,2-pentafluoro-7-(4-methoxyphenyl)heptan-3-one, GK187) bearing a methoxy group at the para position of the phenyl substituent. They

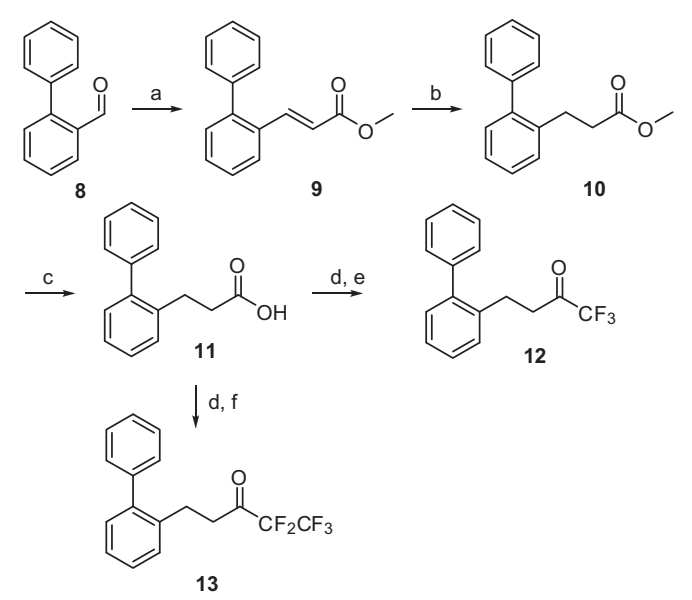

Scheme 2. Reagents and conditions: (a) $\mathrm{CH}_{3} \mathrm{OOCCH}=\mathrm{PPh}_{3}$, dry THF; (b) $\mathrm{H}_{2}, 10 \% \mathrm{Pd} /$ C, MeOH; (c) NaOH $1 \mathrm{~N}, \mathrm{MeOH}$; (d) $(\mathrm{COCl})_{2}, \mathrm{DMF}, \mathrm{CH}_{2} \mathrm{Cl}_{2}$; (e) pyridine, $\left(\mathrm{CF}_{3} \mathrm{CO}\right)_{2} \mathrm{O}$, $\mathrm{CH}_{2} \mathrm{Cl}_{2}, 0{ }^{\circ} \mathrm{C}$ to rt; (f) pyridine, $\left(\mathrm{CF}_{3} \mathrm{CF}_{2} \mathrm{CO}\right)_{2} \mathrm{O}, \mathrm{CH}_{2} \mathrm{Cl}_{2}, 0{ }^{\circ} \mathrm{C}$ to rt.

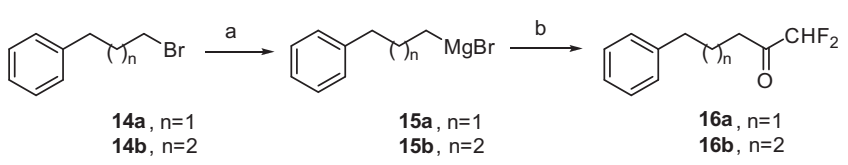

Scheme 3. Reagents and conditions: (a) $\mathrm{Mg}$, dry $\mathrm{Et}_{2} \mathrm{O}$; (b) $\mathrm{CHF}_{2} \mathrm{COOEt}$, dry $\mathrm{Et}_{2} \mathrm{O}$, $-78^{\circ} \mathrm{C}$.

both present $X_{\mathrm{I}}(50)$ values of 0.0001 and they are much more selective to GVIA iPLA 2 when compared to GIVA cPLA 2 and GV sPLA 2 .

Taking into consideration these results, we prepared and tested in vitro a series of other polyfluoroalkyl ketones bearing one or two methoxy groups in different positions of the phenyl group, in order to find even more potent and selective GVIA iPLA 2 inhibitors. However, compounds $\mathbf{5} \mathbf{g}-\mathbf{j}$ and $\mathbf{6 g}-\mathbf{j}$ lost the potency that inhibitors $\mathbf{5 d}$ and $\mathbf{6 d}$ presented. The most potent of this group were compounds $5 \mathbf{j}$ and $\mathbf{6 j}$, bearing a dioxolane ring on the phenyl group.

The structurally restricted analogues of inhibitor FKGK11 12 and 13 did not give optimum potency; instead they were weak, yet selective, $\mathrm{iPLA}_{2}$ inhibitors.

Finally, the two difluoromethyl ketones $\mathbf{1 6 a}$ and $\mathbf{1 6 b}$ that are analogues of FKGK11 presented good selectivity, but low activity, towards GVIA iPLA 2 when compared with GIVA $\mathrm{CPLA}_{2}$ and GV sPLA $_{2}$.

\section{Conclusion}

In the present study, we identified six fluoroketones $(\mathbf{5 b}, \mathbf{5 c}, \mathbf{5 d}$, $\mathbf{6 b}, \mathbf{6 c}$, and $\mathbf{6 d}$ ) that are very potent inhibitors of GVIA iPLA 2 . All of them are more potent than the previous lead inhibitor FKGK11, which has been successfully used in animal models of neurological disorders, ${ }^{38}$ but compounds $\mathbf{5 d}$ and $\mathbf{6 d}$ are also more potent than the most potent PPLA $_{2}$ inhibitor FKGK18 in the literature. Especially, compound $\mathbf{6 d}$ (GK187) is the most potent, but also the most selective $\mathrm{PLA}_{2}$ inhibitor presented, since it shows less that $25 \%$ inhibition against GIVA $\mathrm{CPLA}_{2}$ and $32.8 \%$ against GV $\mathrm{sPLA}_{2}$ at $0.091 \mathrm{~mol}$ fraction.

In conclusion, a series of potent GVIA iPLA $_{2}$ inhibitors was developed. The introduction of a methoxy group at the para position of the phenyl group of the lead compound FKGK11 resulted in the most potent GVIA iPLA $_{2}$ inhibitor ever reported $\left(X_{\mathrm{I}}(50)=0.0001\right)$. By the use of these inhibitors in studies in animal models, the role of GVIA iPLA 2 in inflammatory conditions or neurological diseases may be further explored. Since GVIA iPLA in $_{2}$ emerged as a novel target for drug discovery, the identification of potent and selective iPLA $\mathrm{P}_{2}$ inhibitors is of paramount importance.

\section{Experimental section}

\subsection{General}

Melting points were determined on a Buchi 530 apparatus and are uncorrected. Nuclear magnetic resonance spectra were obtained on a Varian Mercury spectrometer $\left({ }^{1} \mathrm{H}\right.$ NMR recorded at $200 \mathrm{MHz},{ }^{13} \mathrm{C}$ NMR recorded at $50 \mathrm{MHz},{ }^{19} \mathrm{~F}$ NMR recorded at $188 \mathrm{MHz})$ and were recorded in chloroform $\left(\mathrm{CDCl}_{3}\right)$, using $\mathrm{CHCl}_{3}$ residual peak as the ${ }^{1} \mathrm{H}$ internal reference (7.27 ppm); and the central peak of $\mathrm{CDCl}_{3}$ at $77.0 \mathrm{ppm}$ for ${ }^{13} \mathrm{C}$ NMR. All ${ }^{19} \mathrm{~F}$ NMR chemical shifts were referenced to $\mathrm{CFCl}_{3}(0.0 \mathrm{ppm})$. Thin layer chromatography (TLC) plates (silica gel $60 \mathrm{~F}_{254}$ ) and silica gel 60 (230400 mesh) for flash column chromatography were purchased from Merck. Visualization of spots was effected with UV light and/or phosphomolybdic acid, in EtOH stain. Tetrahydrofuran, toluene, and $\mathrm{Et}_{2} \mathrm{O}$ were dried by standard procedures and stored over molecular sieves or $\mathrm{Na}$. All other solvents and chemicals were 
Table 1

Inhibition of $\mathrm{PLA}_{2}$ by fluoroketones ${ }^{\mathrm{a}}$

\begin{tabular}{|c|c|c|c|c|}
\hline \multirow[t]{2}{*}{ Number } & \multicolumn{2}{|c|}{ GVIA iPLA $_{2}$} & \multirow{2}{*}{$\begin{array}{l}\text { GIVA cPLA }_{2} \\
\text { \% Inhibition at } 0.091\end{array}$} & \multirow{2}{*}{$\begin{array}{l}\text { GV sPLA } \\
\text { \% Inhibition at } 0.091\end{array}$} \\
\hline & \% Inhibition at 0.091 & $X_{\mathrm{I}}(50)$ & & \\
\hline FKGK11 $1^{37}$ & 99.4 & $0.0014 \pm 0.0001$ & N.D. & 28.0 \\
\hline FKGK18 $8^{37}$ & 99.9 & $0.0002 \pm 0.0000$ & 80.8 & 63.0 \\
\hline $5 \mathbf{a}$ & 98.7 & $0.0018 \pm 0.0002$ & 77.4 & 31.9 \\
\hline $\mathbf{6 a}$ & 96.4 & $0.0034 \pm 0.0002$ & 64.0 & 29.4 \\
\hline $7 \mathbf{a}$ & 76.7 & & 60.4 & 57.8 \\
\hline $5 \mathbf{b}$ & 98.5 & $0.0002 \pm 0.0000$ & 41.4 & N.D. \\
\hline $6 \mathbf{b}$ & 98.2 & $0.0003 \pm 0.0001$ & N.D. & 29.3 \\
\hline $5 c$ & 99.9 & $0.0002 \pm 0.0000$ & 83.9 & 30.4 \\
\hline 6c & 98.9 & $0.0003 \pm 0.0001$ & 62.5 & 36.9 \\
\hline $5 d$ & 99.8 & $0.0001 \pm 0.0000$ & 54.3 & N.D. \\
\hline 6d & 99.8 & $0.0001 \pm 0.0000$ & N.D. & 32.8 \\
\hline $5 e$ & 97.9 & $0.0189 \pm 0.0045$ & $96.5 X_{\mathrm{I}}(50): 0.0074 \pm 0.0003$ & 40.5 \\
\hline $6 \mathbf{e}$ & 94.6 & $0.0134 \pm 0.0017$ & 72.6 & 38.3 \\
\hline $\mathbf{5 f}$ & 92.6 & & 85.5 & 41.7 \\
\hline 6f & 92.5 & & 54.7 & 63.1 \\
\hline $5 g$ & 89.6 & & 64.3 & N.D. \\
\hline $6 \mathrm{~g}$ & 95.6 & $0.0553 \pm 0.0056$ & 35.6 & 38.7 \\
\hline $5 h$ & 62.5 & & 28.8 & N.D. \\
\hline $6 h$ & 78.3 & & N.D. & N.D. \\
\hline $5 \mathbf{i}$ & 82.8 & & 58.9 & N.D. \\
\hline $6 \mathbf{i}$ & 95.5 & $0.0263 \pm 0.0047$ & 30.5 & 39.1 \\
\hline $5 \mathbf{j}$ & 98.7 & $0.0025 \pm 0.0002$ & 41.2 & N.D. \\
\hline $6 \mathbf{j}$ & 99.5 & $0.0019 \pm 0.0003$ & 38.3 & 29.4 \\
\hline 12 & 75.0 & & N.D. & \\
\hline 13 & 90.4 & & N.D. & \\
\hline $16 \mathbf{a}$ & 86.5 & & N.D. & N.D. \\
\hline $16 b$ & 87.4 & & N.D. & N.D. \\
\hline
\end{tabular}

a Average percent inhibition and standard error $(n=3)$ are reported for each compound at 0.091 mol fraction. $X_{\mathrm{I}}(50)$ values were determined for inhibitors with greater than $95 \%$ inhibition. N.D. signifies compounds with less than $25 \%$ inhibition (or no detectable inhibition).

reagent grade and used without further purification. All the products gave satisfactory elemental analysis results.

\subsection{Chemistry}

\subsubsection{Synthesis of trifluoromethyl ketones}

Oxalyl chloride $(1.5 \mathrm{~mL}, 3 \mathrm{mmol})$ and $N, N$-dimethylformamide $(40 \mu \mathrm{L})$ were added to a solution of carboxylic acid $\mathbf{4 a}-\mathbf{j}$ or $\mathbf{1 1}$ $(1 \mathrm{mmol})$ in dry dichloromethane $(40 \mathrm{~mL})$. After $2 \mathrm{~h}$ stirring at room temperature, the solvent and excess reagent were evaporated under reduced pressure and the residue was dissolved in dry dichloromethane $(10 \mathrm{~mL})$. Pyridine $(0.64 \mathrm{~mL}, 8 \mathrm{mmol})$ and trifluoroacetic anhydride $(0.85 \mathrm{~mL}, 6 \mathrm{mmol})$ were added dropwise to this solution at $0{ }^{\circ} \mathrm{C}$ consecutively. After stirring at $0{ }^{\circ} \mathrm{C}$ for $30 \mathrm{~min}$ and at room temperature for $1.5 \mathrm{~h}$, the reaction mixture was cooled again at $0{ }^{\circ} \mathrm{C}$ and water $(2 \mathrm{~mL})$ was added dropwise. After stirring for $30 \mathrm{~min}$ at $0{ }^{\circ} \mathrm{C}$ and another $30 \mathrm{~min}$ at room temperature, the reaction mixture was diluted with dichloromethane $(10 \mathrm{~mL})$. The organic phase was then washed with brine and dried $\left(\mathrm{Na}_{2} \mathrm{SO}_{4}\right)$. The solvent was evaporated under reduced pressure, and the residual oil was purified by flash column chromatography [EtOAc-petroleum ether (bp $40-60{ }^{\circ} \mathrm{C}$ ) $5 / 95$ to $1 / 9$ ].

4.2.1.1. 1,1,1-Trifluoro-6-(naphthalen-1-yl)hexan-2-one (5a). Yield 26\%; Yellow oil; ${ }^{1} \mathrm{H}$ NMR $\left(200 \mathrm{MHz}, \mathrm{CDCl}_{3}\right): \delta$ 8.10-7.30 (m, 7H, arom), 3.13 (t, $2 \mathrm{H}, \mathrm{CH}_{2}, J=5.8 \mathrm{~Hz}$ ), 2.77 (t, $2 \mathrm{H}$, $\left.\mathrm{CH}_{2}, J=5.8 \mathrm{~Hz}\right), 1.86-1.79\left(\mathrm{~m}, 4 \mathrm{H}, \mathrm{CH}_{2}\right) ;{ }^{13} \mathrm{C} \mathrm{NMR}\left(50 \mathrm{MHz}, \mathrm{CDCl}_{3}\right)$ : $\delta 191.39(\mathrm{q}, \mathrm{CO}, J=35 \mathrm{~Hz}), 137.62,133.87,131.66,128.82,126.78$, 125.98, 125.83, 125.49, 123.55, $115.51\left(\mathrm{q}, \mathrm{CF}_{3}, J=290 \mathrm{~Hz}\right), 36.20$, 32.67, 29.71, 22.36; ${ }^{19} \mathrm{~F}$ NMR $\left(188 \mathrm{MHz}, \mathrm{CDCl}_{3}\right): \delta-79.7\left(\mathrm{CF}_{3}\right)$; MS (ESI) $\mathrm{m} / \mathrm{z}(\%)$ : $279.2\left([\mathrm{M}-\mathrm{H}]^{-}, 100\right)$; Anal. Calcd for $\mathrm{C}_{16} \mathrm{H}_{15} \mathrm{~F}_{3} \mathrm{O}$ : C, 68.56; $\mathrm{H}, 5.39$. Found: $\mathrm{C}, 68.47 ; \mathrm{H}, 5.42$.

4.2.1.2. 1,1,1-Trifluoro-6-(4-fluorophenyl)hexan-2-one (5b).
7.17-6.93 (m, 4H, arom), $2.74\left(\mathrm{t}, 2 \mathrm{H}, \mathrm{CH}_{2}, J=6.6 \mathrm{~Hz}\right), 2.63(\mathrm{t}, 2 \mathrm{H}$, $\left.\mathrm{CH}_{2}, J=7.2 \mathrm{~Hz}\right), 1.80-1.56\left(\mathrm{~m}, 4 \mathrm{H}, \mathrm{CH}_{2} \mathrm{CH}_{2}\right) ;{ }^{13} \mathrm{C} \mathrm{NMR}(50 \mathrm{MHz}$, $\left.\mathrm{CDCl}_{3}\right): \delta 191.3$ (q, CO, J= 45 Hz), 161.3 (d, C-F, J = $\left.242 \mathrm{~Hz}\right), 137.2$, $129.6(\mathrm{~d}, J=8 \mathrm{~Hz}), 115.5\left(\mathrm{q}, \mathrm{CF}_{3}, J=291 \mathrm{~Hz}\right), 115.1(\mathrm{~d}, J=21 \mathrm{~Hz})$, 36.1, 34.6, 30.5, 21.8; ${ }^{19} \mathrm{~F}$ NMR (188 MHz, $\left.\mathrm{CDCl}_{3}\right): \delta-79.8\left(\mathrm{CF}_{3}\right)$, -118.0 (F); MS (ESI) $m / z(\%): 247.2\left([\mathrm{M}-\mathrm{H}]^{-}, 85\right)$; Anal. Calcd for $\mathrm{C}_{12} \mathrm{H}_{12} \mathrm{~F}_{4} \mathrm{O}$ : C, 58.07; $\mathrm{H}, 4.87$. Found: C, 58.16; H, 4.85.

4.2.1.3. 1,1,1-Trifluoro-6-(4-(trifluoromethyl)phenyl)hexan-2one (5c). Yield 16\%; Yellow oil; ${ }^{1} \mathrm{H}$ NMR $\left(200 \mathrm{MHz}, \mathrm{CDCl}_{3}\right): \delta$ 7.53 (d, 2H, arom, $J=8.0 \mathrm{~Hz}$ ), 7.27 (d, $2 \mathrm{H}$, arom, $J=8.0 \mathrm{~Hz}$ ), 2.71 $\left(\mathrm{t}, 4 \mathrm{H}, \mathrm{CH}_{2}, J=7.0 \mathrm{~Hz}\right), 1.78-1.60\left(\mathrm{~m}, 4 \mathrm{H}, \mathrm{CH}_{2}\right) ;{ }^{13} \mathrm{C} \mathrm{NMR}$ $\left(50 \mathrm{MHz}, \mathrm{CDCl}_{3}\right): \delta 191.4(\mathrm{t}, \mathrm{CO}, J=35 \mathrm{~Hz}), 145.9,132.6,128.2$, $125.6,124.5\left(\mathrm{q}, \mathrm{CF}_{3}, J=270 \mathrm{~Hz}\right), \delta 115.8\left(\mathrm{q}, \mathrm{CF}_{3}, J=290 \mathrm{~Hz}\right), 36.2$, 35.5, 30.3, 22.1; ${ }^{19} \mathrm{~F}$ NMR $\left(188 \mathrm{MHz}, \mathrm{CDCl}_{3}\right): \delta-62.8\left(\mathrm{CF}_{3}\right),-79.8$ $\left(\mathrm{CF}_{3}\right)$; $\mathrm{MS}(\mathrm{ESI}) \mathrm{m} / \mathrm{z}(\%): 297.1\left([\mathrm{M}-\mathrm{H}]^{-}, 100\right)$; Anal. Calcd for $\mathrm{C}_{13} \mathrm{H}_{12} \mathrm{~F}_{6} \mathrm{O}$ : C, 52.36; $\mathrm{H}, 4.06$. Found: $\mathrm{C}, 52.48 ; \mathrm{H}, 4.01$.

4.2.1.4. 1,1,1-Trifluoro-6-(4-methoxyphenyl)hexan-2-one (5d) ${ }^{\mathbf{4 3 , 4 4}}$. Yield 40\%; Yellow oil; ${ }^{1} \mathrm{H}$ NMR (200 $\left.\mathrm{MHz} \mathrm{CDCl}_{3}\right): \delta$ 7.09 (d, $2 \mathrm{H}$, arom, $J=8.6 \mathrm{~Hz}$ ), 6.83 (d, $2 \mathrm{H}$, arom, $J=8.6 \mathrm{~Hz}$ ), 3.79 $\left(\mathrm{s}, 3 \mathrm{H}, \mathrm{OCH}_{3}\right), 2.74\left(\mathrm{t}, 2 \mathrm{H}, \mathrm{CH}_{2}, J=6.6 \mathrm{~Hz}\right), 2.68\left(\mathrm{t}, 2 \mathrm{H}, \mathrm{CH}_{2}\right.$, $J=6.8 \mathrm{~Hz}), 1.80-1.60\left(\mathrm{~m}, 4 \mathrm{H}, \mathrm{CH}_{2}\right) ;{ }^{13} \mathrm{C} \mathrm{NMR}\left(50 \mathrm{MHz}, \mathrm{CDCl}_{3}\right): \delta$ $191.4(\mathrm{q}, \mathrm{CO}, J=34 \mathrm{~Hz}), 157.8,133.6,129.9,115.5\left(\mathrm{q}, \mathrm{CF}_{3}\right.$, $J=290 \mathrm{~Hz}), 113.7,55.2,36.2,34.5,30.6,21.9 ;{ }^{19} \mathrm{~F} \mathrm{NMR}(188 \mathrm{MHz}$ $\left.\mathrm{CDCl}_{3}\right): \delta-79.8\left(\mathrm{CF}_{3}\right)$. MS (ESI) $\mathrm{m} / z(\%): 259.2\left([\mathrm{M}-\mathrm{H}]^{-}, 100\right)$; Anal. Calcd for $\mathrm{C}_{13} \mathrm{H}_{15} \mathrm{~F}_{3} \mathrm{O}_{2}$ : C, 60.00; $\mathrm{H}, 5.81$. Found: $\mathrm{C}, 60.11 ; \mathrm{H}, 5.76$.

4.2.1.5.

6-(Biphenyl-4-yl)-1,1,1-trifluorohexan-2-one

(5e). Yield 39\%; Yellowish oil; ${ }^{1} \mathrm{H}$ NMR $\left(200 \mathrm{MHz}, \mathrm{CDCl}_{3}\right): \delta$ 7.70-7.20 (m, 9H, arom), 2.80-2.60 (m, 4H, $\left.\mathrm{CH}_{2}\right), 1.90-1.60(\mathrm{~m}$, $\left.4 \mathrm{H}, \mathrm{CH}_{2}\right) ;{ }^{13} \mathrm{C}$ NMR $\left(50 \mathrm{MHz}, \mathrm{CDCl}_{3}\right): \delta 191.4(\mathrm{q}, \mathrm{CO}, J=35 \mathrm{~Hz})$, $140.9,140.7,138.9,128.9,128.8,128.7,127.2,127.1,127.0$, 126.9, $115.5\left(\mathrm{q}, \mathrm{CF}_{3}, J=290 \mathrm{~Hz}\right), 36.2,35.1,30.4,22.0 ;{ }^{19} \mathrm{~F}$ NMR $\left(188 \mathrm{MHz}, \mathrm{CDCl}_{3}\right): \delta-79.7\left(\mathrm{CF}_{3}\right)$; MS (ESI) $\mathrm{m} / z(\%): 305.2\left([\mathrm{M}-\mathrm{H}]^{-}\right.$, 
100); Anal. Calcd for $\mathrm{C}_{18} \mathrm{H}_{17} \mathrm{~F}_{3} \mathrm{O}$ : C, 70.58; H, 5.59. Found: C, 70.69; H, 5.54 .

\subsubsection{1,1,1-Trifluoro-6-(6-methoxynaphthalen-2-yl)hexan-2- one (5f). Yield 53\%; Yellow solid; mp 51-53 ${ }^{\circ} \mathrm{C}$; ${ }^{1} \mathrm{H}$ NMR $\left(200 \mathrm{MHz}, \mathrm{CDCl}_{3}\right): \delta 7.70(\mathrm{~d}, 2 \mathrm{H}$, arom, $J=8.2 \mathrm{~Hz}), 7.55(\mathrm{~s}, 1 \mathrm{H}$, arom), $7.30(\mathrm{~d}, 1 \mathrm{H}$, arom, $J=8.0 \mathrm{~Hz}), 7.16(\mathrm{~d}, 1 \mathrm{H}$, arom, $J=8.2 \mathrm{~Hz}$ ), $7.14\left(\mathrm{~s}, 1 \mathrm{H}\right.$, arom), $3.92\left(\mathrm{~s}, 3 \mathrm{H}, \mathrm{OCH}_{3}\right), 2.90-2.55\left(\mathrm{~m}, 4 \mathrm{H}, \mathrm{CH}_{2}\right)$, 1.90-1.50 (m, 4H, $\left.\mathrm{CH}_{2}\right) ;{ }^{13} \mathrm{C}$ NMR $\left(50 \mathrm{MHz}, \mathrm{CDCl}_{3}\right): \delta 191.4(\mathrm{q}$, $\mathrm{CO}, J=35 \mathrm{~Hz}), 157.2,136.7,133.0,129.0,128.8,127.6,126.8$, 126.2, 118.7, $115.5\left(\mathrm{q}, \mathrm{CF}_{3}, J=290 \mathrm{~Hz}\right), 105.5,55.2,36.1,35.3$, 30.3, 21.9; ${ }^{19} \mathrm{~F}$ NMR (188 MHz, $\left.\mathrm{CDCl}_{3}\right): \delta-79.7\left(\mathrm{CF}_{3}\right)$; MS (ESI) $\mathrm{m} /$ $z$ (\%): $309.3\left([\mathrm{M}-\mathrm{H}]^{-}, 100\right)$; Anal. Calcd for $\mathrm{C}_{17} \mathrm{H}_{17} \mathrm{~F}_{3} \mathrm{O}_{2}$ : C, 65.80; H, 5.52. Found: C, 65.88; H, 5.48 .}

4.2.1.7. 6-(2,4-Dimethoxyphenyl)-1,1,1-trifluorohexan-2-one (5g). Yield 16\%; Yellow oil; ${ }^{1} \mathrm{H}$ NMR $\left(200 \mathrm{MHz}, \mathrm{CDCl}_{3}\right): \delta$ $7.02(\mathrm{~d}, 1 \mathrm{H}$, arom, $J=7.2 \mathrm{~Hz}), 6.45(\mathrm{~s}, 1 \mathrm{H}$, arom), $6.42(\mathrm{~d}, 1 \mathrm{H}$, arom, $J=7.2 \mathrm{~Hz}), 3.80\left(\mathrm{~s}, 6 \mathrm{H}, \mathrm{OCH}_{3}\right), 2.75\left(\mathrm{t}, 2 \mathrm{H}, \mathrm{CH}_{2}, J=6.6 \mathrm{~Hz}\right), 2.58(\mathrm{t}$, $\left.2 \mathrm{H}, \mathrm{CH}_{2}, J=6.8 \mathrm{~Hz}\right), 1.80-1.50\left(\mathrm{~m}, 4 \mathrm{H}, \mathrm{CH}_{2}\right) ;{ }^{13} \mathrm{C} \mathrm{NMR}(50 \mathrm{MHz}$, $\left.\mathrm{CDCl}_{3}\right): \delta 191.6(\mathrm{q}, \mathrm{CO}, J=35 \mathrm{~Hz}), 159.2,158.2,129.9,122.4$, $115.5\left(\mathrm{q}, \mathrm{CF}_{3}, J=291 \mathrm{~Hz}\right), 103.7,98.4,55.3,55.2,36.2,29.1,29.0$, 21.9; ${ }^{19} \mathrm{~F}$ NMR (188 MHz, $\left.\mathrm{CDCl}_{3}\right): \delta-79.7\left(\mathrm{CF}_{3}\right)$; MS (ESI) $\mathrm{m} / z(\%)$ : $289.3\left([\mathrm{M}-\mathrm{H}]^{-}, 100\right)$; Anal. Calcd for $\mathrm{C}_{14} \mathrm{H}_{17} \mathrm{~F}_{3} \mathrm{O}_{3}$ : C, 57.93; $\mathrm{H}$, 5.90. Found: C, 57.87; H, 5.92.

4.2.1.8. 6-(3,4-Dimethoxyphenyl)-1,1,1-trifluorohexan-2-one (5h). Yield 26\%; Yellow oil; ${ }^{1} \mathrm{H}$ NMR (200 $\left.\mathrm{MHz}, \mathrm{CDCl}_{3}\right): \delta$ 6.90-6.50 (m, 3H, arom), $3.83\left(\mathrm{~s}, 3 \mathrm{H}, \mathrm{OCH}_{3}\right), 3.81\left(\mathrm{~s}, 3 \mathrm{H}, \mathrm{OCH}_{3}\right)$, $2.70\left(\mathrm{t}, 2 \mathrm{H}, \mathrm{CH}_{2}, J=5.8 \mathrm{~Hz}\right), 2.55\left(\mathrm{t}, 2 \mathrm{H}, \mathrm{CH}_{2}, J=7.0 \mathrm{~Hz}\right), 1.85-1.40$ $\left(\mathrm{m}, 4 \mathrm{H}, \mathrm{CH}_{2}\right) ;{ }^{13} \mathrm{C} \mathrm{NMR}\left(50 \mathrm{MHz}, \mathrm{CDCl}_{3}\right): \delta 191.3$ (q, CO, $J=35 \mathrm{~Hz}), 148.7,147.1,134.1,120.0,115.4\left(\mathrm{q}, \mathrm{CF}_{3}, J=291 \mathrm{~Hz}\right)$, $111.4,111.0,55.7,55.6,36.1,35.0,30.5,21.8 ;{ }^{19} \mathrm{~F}$ NMR $(188 \mathrm{MHz}$, $\left.\mathrm{CDCl}_{3}\right): \delta-79.8\left(\mathrm{CF}_{3}\right)$; MS (ESI) $\mathrm{m} / z(\%): 289.1\left([\mathrm{M}-\mathrm{H}]^{-}, 100\right)$; Anal. Calcd for $\mathrm{C}_{14} \mathrm{H}_{17} \mathrm{~F}_{3} \mathrm{O}_{3}$ : C, 57.93; H, 5.90. Found: C, 57.82; H, 5.94 .

4.2.1.9. 1,1,1-Trifluoro-6-(2-methoxyphenyl)hexan-2-one (5i). Yield 29\%; Yellowish oil; ${ }^{1} \mathrm{H}$ NMR (200 $\left.\mathrm{MHz}, \mathrm{CDCl}_{3}\right): \delta$ 7.30-7.05 (m, 2H, arom), 6.95-6.75 (m, 2H, arom), $3.82(\mathrm{~s}, 3 \mathrm{H}$, $\left.\mathrm{OCH}_{3}\right), 2.82-2.54\left(\mathrm{~m}, 4 \mathrm{H}, \mathrm{CH}_{2}\right), 1.83-1.50\left(\mathrm{~m}, 4 \mathrm{H}, \mathrm{CH}_{2}\right) ;{ }^{13} \mathrm{C} \mathrm{NMR}$ $\left(50 \mathrm{MHz}, \mathrm{CDCl}_{3}\right): \delta 191.6(\mathrm{q}, \mathrm{CO}, J=35 \mathrm{~Hz}), 157.3,130.0,129.8$, 127.1, 120.3, $115.5\left(\mathrm{q}, \mathrm{CF}_{3}, J=291 \mathrm{~Hz}\right), 110.1,55.1,36.1,29.6$, 28.8, 22.0; ${ }^{19} \mathrm{~F}$ NMR (188 MHz, $\left.\mathrm{CDCl}_{3}\right): \delta-79.9\left(\mathrm{CF}_{3}\right)$. MS (ESI) $\mathrm{m} /$ $z$ (\%): $259.2\left([\mathrm{M}-\mathrm{H}]^{-}, 100\right)$; Anal. Calcd for $\mathrm{C}_{13} \mathrm{H}_{15} \mathrm{~F}_{3} \mathrm{O}_{2}: \mathrm{C}, 60.00$; H, 5.81. Found: C, 59.87; H, 5.87.

\subsubsection{6-(Benzo[d][1,3]dioxol-5-yl)-1,1,1-trifluorohexan-2-} one (5j). Yield 70\%; Yellow oil; ${ }^{1} \mathrm{H}$ NMR (200 $\left.\mathrm{MHz}, \mathrm{CDCl}_{3}\right): \delta$ 6.82-6.42 (m, 3H, arom), $5.92\left(\mathrm{~s}, 2 \mathrm{H}, \mathrm{OCH}_{2} \mathrm{O}\right), 2.73\left(\mathrm{t}, 2 \mathrm{H}, \mathrm{CH}_{2}\right.$, $J=6.6 \mathrm{~Hz}), 2.57\left(\mathrm{t}, 2 \mathrm{H}, \mathrm{CH}_{2}, J=6.6 \mathrm{~Hz}\right), 1.90-1.50\left(\mathrm{~m}, 4 \mathrm{H}, \mathrm{CH}_{2}\right)$; ${ }^{13} \mathrm{C} \mathrm{NMR}\left(50 \mathrm{MHz}, \mathrm{CDCl}_{3}\right): \delta 191.4(\mathrm{q}, \mathrm{CO}, J=35 \mathrm{~Hz}), 147.6,145.7$, $135.4,121.0,115.5$ (q, $\left.\mathrm{CF}_{3}, J=291 \mathrm{~Hz}\right), 108.7,108.1,100.7,36.1$, 35.1, 30.6, 21.8; ${ }^{19} \mathrm{~F}$ NMR $\left(188 \mathrm{MHz}, \mathrm{CDCl}_{3}\right): \delta-79.8\left(\mathrm{CF}_{3}\right)$; $\mathrm{MS}$ (ESI) $\mathrm{m} / z$ (\%): $273.4\left([\mathrm{M}+\mathrm{H}]^{+}, 100\right)$; Anal. Calcd for $\mathrm{C}_{14} \mathrm{H}_{15} \mathrm{~F}_{3} \mathrm{O}_{2}: \mathrm{C}$, 61.76; H, 5.55. Found: C, 61.87; H, 5.49.

4.2.1.11. 4-(Biphenyl-2-yl)-1,1,1-trifluorobutan-2-one (12). Yield 67\%; Yellow oil; ${ }^{1} \mathrm{H}$ NMR $\left(200 \mathrm{MHz}, \mathrm{CDCl}_{3}\right): \delta$ 7.60-7.10 (m, 9H, arom), $3.04\left(\mathrm{t}, 2 \mathrm{H}, \mathrm{CH}_{2}, J=7.0 \mathrm{~Hz}\right), 2.83(\mathrm{t}, 2 \mathrm{H}$, $\left.\mathrm{CH}_{2}, J=7.0 \mathrm{~Hz}\right) ;{ }^{13} \mathrm{C}$ NMR $\left(50 \mathrm{MHz}, \mathrm{CDCl}_{3}\right): \delta 190.5$ (q, CO, $J=35 \mathrm{~Hz}), 142.0,141.1,136.6,130.4,128.4,127.7,127.2,126.7$, $115.4\left(\mathrm{q}, \mathrm{CF}_{3}, J=291 \mathrm{~Hz}\right), 37.3,26.0 ;{ }^{19} \mathrm{~F} \mathrm{NMR}\left(188 \mathrm{MHz}, \mathrm{CDCl}_{3}\right)$ : $\delta-79.7\left(\mathrm{CF}_{3}\right)$. MS (ESI) $m / z(\%): 277.2\left([\mathrm{M}-\mathrm{H}]^{-}, 100\right)$; Anal. Calcd for $\mathrm{C}_{16} \mathrm{H}_{13} \mathrm{~F}_{3} \mathrm{O}$ : C, 69.06; $\mathrm{H}, 4.71$. Found: $\mathrm{C}, 69.15 ; \mathrm{H}, 4.68$.

\subsubsection{Synthesis of pentafluoroethyl ketones}

The synthesis of pentafluoroethyl ketones was carried out following the procedure described above for trifluoromethyl ketones, except that pentafluoropropionic anhydride was used instead of trifluoroacetic anhydride. The products were purified by flash column chromatography [EtOAc-petroleum ether (bp 40-60 ${ }^{\circ} \mathrm{C}$ ) 5/95 to $1 / 9]$.

4.2.2.1. 1,1,1,2,2-Pentafluoro-7-(naphthalen-1-yl)heptan-3-one (6a). Yield 65\%; Yellow oil; ${ }^{1} \mathrm{H}$ NMR (200 $\left.\mathrm{MHz}, \mathrm{CDCl}_{3}\right): \delta$ 8.06-7.32 (m, 7H, arom), $3.13\left(\mathrm{t}, 2 \mathrm{H}, \mathrm{CH}_{2}, J=7.2 \mathrm{~Hz}\right), 2.81(\mathrm{t}, 2 \mathrm{H}$, $\left.\mathrm{CH}_{2}, J=7.0 \mathrm{~Hz}\right), 1.86-1.80\left(\mathrm{~m}, 4 \mathrm{H}, \mathrm{CH}_{2}\right) ;{ }^{13} \mathrm{C} \mathrm{NMR}\left(50 \mathrm{MHz}, \mathrm{CDCl}_{3}\right)$ : $\delta 194.2(\mathrm{t}, \mathrm{CO}, J=27 \mathrm{~Hz}), 137.6,133.9,131.7,128.8,126.8,126.0$, 125.8, 125.5, 123.5, $117.8\left(\mathrm{qt}, \mathrm{CF}_{3}, J_{1}=285 \mathrm{~Hz}, J_{2}=34 \mathrm{~Hz}\right), 109.5$ (tq, $\left.\mathrm{CF}_{2}, J_{1}=265 \mathrm{~Hz}, J_{2}=38 \mathrm{~Hz}\right), 37.2,32.7,29.7,22.3 ;{ }^{19} \mathrm{~F}$ NMR $\left(188 \mathrm{MHz}, \mathrm{CDCl}_{3}\right): \delta-82.3\left(\mathrm{CF}_{3}\right),-123.7\left(\mathrm{CF}_{2}\right)$; $\mathrm{MS}(\mathrm{ESI}) \mathrm{m} / z(\%)$ : $329.2\left([\mathrm{M}-\mathrm{H}]^{-}, 100\right)$; Anal. Calcd for $\mathrm{C}_{17} \mathrm{H}_{15} \mathrm{~F}_{5} \mathrm{O}: \mathrm{C}, 61.82 ; \mathrm{H}$, 4.58. Found: C, 61.87; H, 4.55 .

\subsubsection{1,1,1,2,2-Pentafluoro-7-(4-fluorophenyl)heptan-3-one} (6b). Yield 53\%; Yellow oil; ${ }^{1} \mathrm{H}$ NMR (200 MHz, $\left.\mathrm{CDCl}_{3}\right): \delta$ 7.20-7.00 (m, 2H, arom), 6.98-6.80 (m, 2H, arom), $2.78(\mathrm{t}, 2 \mathrm{H}$, $\left.\mathrm{CH}_{2}, J=6.8 \mathrm{~Hz}\right), 2.62\left(\mathrm{t}, 2 \mathrm{H}, \mathrm{CH}_{2}, J=7.0 \mathrm{~Hz}\right), 1.82-1.60(\mathrm{~m}, 4 \mathrm{H}$, $\left.\mathrm{CH}_{2}\right) ;{ }^{13} \mathrm{C}$ NMR $\left(50 \mathrm{MHz}, \mathrm{CDCl}_{3}\right): \delta 194.2(\mathrm{t}, \mathrm{CO}, J=24 \mathrm{~Hz}), 161.3$ (d, C-F, $J=242 \mathrm{~Hz}), 137.2,129.6(\mathrm{~d}, J=8 \mathrm{~Hz}), 115.1(\mathrm{~d}, J=21 \mathrm{~Hz})$, 122.0-100.0 (m, $\left.\mathrm{CF}_{2}, \mathrm{CF}_{3}\right), 37.1,34.7,30.5,21.8 ;{ }^{19} \mathrm{~F}$ NMR $\left(188 \mathrm{MHz}, \mathrm{CDCl}_{3}\right): \delta-82.3\left(\mathrm{CF}_{3}\right),-118.0(\mathrm{~F}),-123.8\left(\mathrm{CF}_{2}\right) ; \mathrm{MS}$ (ESI) $\mathrm{m} / \mathrm{z}(\%): 297.1\left([\mathrm{M}-\mathrm{H}]^{-}, 100\right)$; Anal. Calcd for $\mathrm{C}_{13} \mathrm{H}_{12} \mathrm{~F}_{6} \mathrm{O}: \mathrm{C}$, 52.36; H, 4.06. Found: C, 52.42; H, 4.03.

4.2.2.3. 1,1,1,2,2-Pentafluoro-7-(4-(trifluoromethyl)phenyl)heptan-3-one (6c). Yield 65\%; Yellow oil; ${ }^{1} \mathrm{H}$ NMR $(200 \mathrm{MHz}$, $\left.\mathrm{CDCl}_{3}\right): \delta 7.57(\mathrm{~d}, 2 \mathrm{H}$, arom, $J=5.2 \mathrm{~Hz}), 7.31(\mathrm{~d}, 2 \mathrm{H}$, arom, $J=5.2 \mathrm{~Hz}), 2.81\left(\mathrm{t}, 2 \mathrm{H}, \mathrm{CH}_{2}, J=4.4 \mathrm{~Hz}\right), 2.74\left(\mathrm{t}, 2 \mathrm{H}, \mathrm{CH}_{2}\right.$, $J=4.4 \mathrm{~Hz}), 1.80-1.66\left(\mathrm{~m}, 4 \mathrm{H}, \mathrm{CH}_{2}\right) ;{ }^{13} \mathrm{C} \mathrm{NMR}\left(50 \mathrm{MHz}, \mathrm{CDCl}_{3}\right): \delta$ $194.1(\mathrm{t}, \mathrm{CO}, \mathrm{J}=27 \mathrm{~Hz}), 145.7,132.4,129.3,128.6,128.0,125.3$ (q, $\left.\mathrm{C}^{-\mathrm{CF}_{3}}, J=4 \mathrm{~Hz}\right), 121.6,117.8\left(\mathrm{qt}, \mathrm{CF}_{3}, J_{1}=285 \mathrm{~Hz}, J_{2}=34 \mathrm{~Hz}\right)$, $109.5\left(\mathrm{tq}, \mathrm{CF}_{2}, J_{1}=265 \mathrm{~Hz}, J_{2}=38 \mathrm{~Hz}\right), 37.1,35.4,30.0,21.8 ;{ }^{19} \mathrm{~F}$ $\operatorname{NMR}\left(188 \mathrm{MHz}, \mathrm{CDCl}_{3}\right): \delta-62.8\left(\mathrm{CF}_{3}\right),-82.4\left(\mathrm{CF}_{3}\right),-123.8\left(\mathrm{CF}_{2}\right)$; MS (ESI) $m / z(\%)$ : $347.1\left([\mathrm{M}-\mathrm{H}]^{-}, 95\right)$; Anal. Calcd for $\mathrm{C}_{14} \mathrm{H}_{12} \mathrm{~F}_{8} \mathrm{O}$ : C, 48.29; H, 3.47. Found: C, 48.38; H, 3.43.

4.2.2.4. 1,1,1,2,2-Pentafluoro-7-(4-methoxyphenyl)heptan-3one (6d). Yield 31\%; Colorless oil; ${ }^{1} \mathrm{H}$ NMR (200 $\left.\mathrm{MHz}, \mathrm{CDCl}_{3}\right)$ : $\delta 7.12(\mathrm{~d}, 2 \mathrm{H}$, arom, $J=5.6 \mathrm{~Hz}), 6.87(\mathrm{~d}, 2 \mathrm{H}$, arom, $J=5.8 \mathrm{~Hz}), 3.83(\mathrm{~s}$, $\left.3 \mathrm{H}, \mathrm{OCH}_{3}\right), 2.79\left(\mathrm{t}, 2 \mathrm{H}, \mathrm{CH}_{2}, J=6.6 \mathrm{~Hz}\right), 2.62\left(\mathrm{t}, 2 \mathrm{H}, \mathrm{CH}_{2}, J=6.8 \mathrm{~Hz}\right)$, $1.79-1.61\left(\mathrm{~m}, 4 \mathrm{H}, \mathrm{CH}_{2}\right) ;{ }^{13} \mathrm{C} \mathrm{NMR}\left(50 \mathrm{MHz}, \mathrm{CDCl}_{3}\right): \delta 194.3(\mathrm{t}, \mathrm{CO}$, $J=27 \mathrm{~Hz}), 157.8,133.7,129.2,113.8,122.0-100.0\left(\mathrm{~m}, \mathrm{CF}_{2}, \mathrm{CF}_{3}\right)$, 55.2, 37.2, 34.6, 30.6; ${ }^{19} \mathrm{~F}$ NMR (188 $\left.\mathrm{MHz}, \mathrm{CDCl}_{3}\right): \delta-82.3\left(\mathrm{CF}_{3}\right)$, $-123.8\left(\mathrm{CF}_{2}\right)$; MS (ESI) $m / z(\%)$ : $309.2\left([\mathrm{M}-\mathrm{H}]^{-}, 72\right)$; Anal. Calcd for $\mathrm{C}_{14} \mathrm{H}_{15} \mathrm{~F}_{5} \mathrm{O}_{2}$ : C, 54.20; $\mathrm{H}, 4.87$. Found: C, 54.32; $\mathrm{H}, 4.84$.

4.2.2.5. 7-(Biphenyl-4-yl)-1,1,1,2,2-pentafluoroheptan-3-one (6e). Yield 63\%; Yellow low mp solid; mp 32-34 ${ }^{\circ} \mathrm{C} ;{ }^{1} \mathrm{H}$ NMR $\left(200 \mathrm{MHz}, \mathrm{CDCl}_{3}\right): \delta 7.80-7.20\left(\mathrm{~m}, 9 \mathrm{H}\right.$, arom), $2.83\left(\mathrm{t}, 2 \mathrm{H}, \mathrm{CH}_{2}\right.$, $J=6.8 \mathrm{~Hz}), 2.73\left(\mathrm{t}, 2 \mathrm{H}, \mathrm{CH}_{2}, J=7.0 \mathrm{~Hz}\right), 1.95-1.60\left(\mathrm{~m}, 4 \mathrm{H}, \mathrm{CH}_{2}\right)$; ${ }^{13} \mathrm{C}$ NMR $\left(50 \mathrm{MHz}, \mathrm{CDCl}_{3}\right): \delta 194.2(\mathrm{t}, \mathrm{CO}, J=27 \mathrm{~Hz}), 141.0,140.7$, $138.9,128.8,128.7,127.1,127.0,126.9,126.4,125.7,117.8$ (qt, $\left.\mathrm{CF}_{3}, J_{1}=285 \mathrm{~Hz}, J_{2}=34 \mathrm{~Hz}\right), 106.9\left(\mathrm{tq}, \mathrm{CF}_{2}, J_{1}=265 \mathrm{~Hz}, J_{2}=38 \mathrm{~Hz}\right)$, 37.1, 35.1, 30.3, 21.9; ${ }^{19} \mathrm{~F}$ NMR $\left(188 \mathrm{MHz}, \mathrm{CDCl}_{3}\right): \delta-82.3\left(\mathrm{CF}_{3}\right)$, $-123.7\left(\mathrm{CF}_{2}\right)$; MS (ESI) $\mathrm{m} / \mathrm{z}(\%)$ : $355.2\left([\mathrm{M}-\mathrm{H}]^{-}, 100\right)$; Anal. Calcd for $\mathrm{C}_{19} \mathrm{H}_{17} \mathrm{~F}_{5} \mathrm{O}$ : $\mathrm{C}, 64.04 ; \mathrm{H}, 4.81$. Found: $\mathrm{C}, 64.16$; $\mathrm{H}, 4.78$.

4.2.2.6. 1,1,1,2,2-Pentafluoro-7-(6-methoxynaphthalen-2yl)heptan-3-one (6f). $\quad$ Yield $60 \%$; Yellow solid; mp $42-44{ }^{\circ} \mathrm{C}$; ${ }^{1} \mathrm{H}$ NMR (200 MHz, $\mathrm{CDCl}_{3}$ ): $\delta 7.69$ (d, $2 \mathrm{H}$, arom, $J=8.8 \mathrm{~Hz}$ ), 7.54 
(s, $1 \mathrm{H}$, arom) $7.28(\mathrm{~d}, 1 \mathrm{H}$, arom, $J=9.4 \mathrm{~Hz}), 7.15(\mathrm{~d}, 1 \mathrm{H}$, arom, $J=8.2 \mathrm{~Hz}), 7.13(\mathrm{~s}, 1 \mathrm{H}$, arom $), 3.91\left(\mathrm{~s}, 3 \mathrm{H}, \mathrm{OCH}_{3}\right), 2.95-2.60(\mathrm{~m}$, $\left.4 \mathrm{H}, \mathrm{CH}_{2}\right), 1.90-1.60\left(\mathrm{~m}, 4 \mathrm{H}, \mathrm{CH}_{2}\right) ;{ }^{13} \mathrm{C}$ NMR $\left(50 \mathrm{MHz}, \mathrm{CDCl}_{3}\right): \delta$ 194.2 (t, CO, $J=27 \mathrm{~Hz}$ ), 157.2, 136.7, 133.0, 129.0, 128.9, 127.6, 126.8, 126.3, $118.8,117.8\left(\mathrm{qt}, \mathrm{CF}_{3}, J_{1}=285 \mathrm{~Hz}, J_{2}=34 \mathrm{~Hz}\right), 106.9$ (tq, $\left.\mathrm{CF}_{2}, J_{1}=265 \mathrm{~Hz}, J_{2}=38 \mathrm{~Hz}\right), 105.6,55.2,37.2,35.4,30.3,21.9$; ${ }^{19} \mathrm{~F}$ NMR $\left(188 \mathrm{MHz}, \mathrm{CDCl}_{3}\right): \delta-82.3\left(\mathrm{CF}_{3}\right),-123.8\left(\mathrm{CF}_{2}\right)$; MS (ESI) $\mathrm{m} / \mathrm{z}(\%): 359.3\left([\mathrm{M}-\mathrm{H}]^{-}, 100\right)$; Anal. Calcd for $\mathrm{C}_{18} \mathrm{H}_{17} \mathrm{~F}_{5} \mathrm{O}_{2}: \mathrm{C}$, $60.00 ; \mathrm{H}, 4.76$. Found: C, 60.17; H, 4.71.

4.2.2.7. 7-(2,4-Dimethoxyphenyl)-1,1,1,2,2-pentafluoroheptan3-one (6g). Yield 52\%; Yellow oil; ${ }^{1} \mathrm{H}$ NMR (200 $\left.\mathrm{MHz}, \mathrm{CDCl}_{3}\right)$ : $\delta 6.99(\mathrm{~d}, 1 \mathrm{H}$, arom, $J=7.8 \mathrm{~Hz}), 6.42(\mathrm{~s}, 1 \mathrm{H}, \mathrm{arom}), 6.40(\mathrm{~d}, 1 \mathrm{H}$, arom, $J=7.8 \mathrm{~Hz}), 3.77\left(\mathrm{~s}, 6 \mathrm{H}, \mathrm{OCH}_{3}\right), 2.76\left(\mathrm{t}, 2 \mathrm{H}, \mathrm{CH}_{2}, J=6.4 \mathrm{~Hz}\right), 2.55(\mathrm{t}$, $\left.2 \mathrm{H}, \mathrm{CH}_{2}, J=7.0 \mathrm{~Hz}\right), 1.78-1.50\left(\mathrm{~m}, 4 \mathrm{H}, \mathrm{CH}_{2}\right) ;{ }^{13} \mathrm{C} \mathrm{NMR}(50 \mathrm{MHz}$, $\left.\mathrm{CDCl}_{3}\right): \delta 194.4(\mathrm{t}, \mathrm{CO}, \mathrm{J}=26 \mathrm{~Hz}), 159.2,158.2,129.9,122.4,117.8$ (qt, $\left.\mathrm{CF}_{3}, J_{1}=285 \mathrm{~Hz}, J_{2}=34 \mathrm{~Hz}\right), 106.9\left(\mathrm{tq}, \mathrm{CF}_{2}, J_{1}=266 \mathrm{~Hz}\right.$, $\left.J_{2}=38 \mathrm{~Hz}\right), 103.7,98.4,55.3,55.1,37.2,29.0,22.6,21.9 ;{ }^{19} \mathrm{~F} \mathrm{NMR}$ $\left(188 \mathrm{MHz}, \mathrm{CDCl}_{3}\right): \delta-82.3\left(\mathrm{CF}_{3}\right),-123.8\left(\mathrm{CF}_{2}\right)$; $\mathrm{MS}(\mathrm{ESI}) \mathrm{m} / z(\%)$ : $339.3\left([\mathrm{M}-\mathrm{H}]^{-}, 100\right)$; Anal. Calcd for $\mathrm{C}_{15} \mathrm{H}_{17} \mathrm{~F}_{5} \mathrm{O}_{3}$ : C, 52.94; $\mathrm{H}$, 5.04. Found: C, 52.87; H, 5.07 .

\subsubsection{7-(3,4-Dimethoxyphenyl)-1,1,1,2,2-pentafluoroheptan-} 3-one (6h). Yield 48\%; Yellowish oil; ${ }^{1} \mathrm{H}$ NMR $(200 \mathrm{MHz}$, $\left.\mathrm{CDCl}_{3}\right): \delta 6.90-6.60(\mathrm{~m}, 3 \mathrm{H}, \mathrm{arom}), 3.88\left(\mathrm{~s}, 3 \mathrm{H}, \mathrm{OCH}_{3}\right), 3.86(\mathrm{~s}, 3 \mathrm{H}$, $\left.\mathrm{OCH}_{3}\right), 2.78\left(\mathrm{t}, 2 \mathrm{H}, \mathrm{CH}_{2}, J=5.4 \mathrm{~Hz}\right), 2.59\left(\mathrm{t}, 2 \mathrm{H}, \mathrm{CH}_{2}, J=6.4 \mathrm{~Hz}\right)$, 1.90-1.42 (m, 4H, $\left.\mathrm{CH}_{2}\right) ;{ }^{13} \mathrm{C}$ NMR $\left(50 \mathrm{MHz}, \mathrm{CDCl}_{3}\right): \delta 194.2(\mathrm{t}, \mathrm{CO}$, $J=26 \mathrm{~Hz}), 148.8,147.2,134.2,120.1,117.8\left(\mathrm{qt}, \mathrm{CF}_{3}, J_{1}=285 \mathrm{~Hz}\right.$, $\left.J_{2}=34 \mathrm{~Hz}\right), 111.5,111.1,106.8\left(\mathrm{tq}, \mathrm{CF}_{2}, J_{1}=265 \mathrm{~Hz}, J_{2}=38 \mathrm{~Hz}\right)$, 55.8, 55.7, 37.1, 35.0, 30.5, 21.8; ${ }^{19} \mathrm{~F}$ NMR $\left(188 \mathrm{MHz}, \mathrm{CDCl}_{3}\right): \delta$ $-82.4\left(\mathrm{CF}_{3}\right),-123.8\left(\mathrm{CF}_{2}\right)$; MS (ESI) $\mathrm{m} / z(\%)$ : $339.3\left([\mathrm{M}-\mathrm{H}]^{-}\right.$, 100); Anal. Calcd for $\mathrm{C}_{15} \mathrm{H}_{17} \mathrm{~F}_{5} \mathrm{O}_{3}$ : C, 52.94; H, 5.04. Found: $\mathrm{C}$, 52.87; H, 5.09.

4.2.2.9. 1,1,1,2,2-Pentafluoro-7-(2-methoxyphenyl)heptan-3one (6i). Yield 32\%; Yellowish oil; ${ }^{1} \mathrm{H}$ NMR (200 $\left.\mathrm{MHz}, \mathrm{CDCl}_{3}\right)$ : $\delta$ 7.35-7.05 (m, 2H, arom), 6.95-6.75 (m, 2H, arom), $3.81(\mathrm{~s}, 3 \mathrm{H}$, $\left.\mathrm{OCH}_{3}\right), 2.78\left(\mathrm{t}, 2 \mathrm{H}, \mathrm{CH}_{2}, J=6.6 \mathrm{~Hz}\right), 2.63\left(\mathrm{t}, 2 \mathrm{H}, \mathrm{CH}_{2}, J=6.6 \mathrm{~Hz}\right)$, 1.90-1.50 (m, 4H, $\left.\mathrm{CH}_{2}\right) ;{ }^{13} \mathrm{C}$ NMR (50 MHz, $\left.\mathrm{CDCl}_{3}\right): \delta 194.4(\mathrm{t}, \mathrm{CO}$, $J=26 \mathrm{~Hz}), 157.3,130.0,129.8,127.2,120.4,117.8\left(\mathrm{qt}, \mathrm{CF}_{3}\right.$, $\left.J_{1}=285 \mathrm{~Hz}, \quad J_{2}=34 \mathrm{~Hz}\right), \quad 110.2, \quad 109.5 \quad\left(\mathrm{tq}, \quad \mathrm{CF}_{2}, \quad J_{1}=265 \mathrm{~Hz}\right.$, $\left.J_{2}=38 \mathrm{~Hz}\right), 55.1,37.2,29.6,28.8,21.9 ;{ }^{19} \mathrm{~F} \mathrm{NMR}\left(188 \mathrm{MHz}, \mathrm{CDCl}_{3}\right)$ : $\delta-82.4\left(\mathrm{CF}_{3}\right),-123.8\left(\mathrm{CF}_{2}\right)$; MS (ESI) $\mathrm{m} / z(\%)$ : $309.1\left([\mathrm{M}-\mathrm{H}]^{-}, 85\right)$; Anal. Calcd for $\mathrm{C}_{14} \mathrm{H}_{15} \mathrm{~F}_{5} \mathrm{O}_{2}$ : C, 54.20; $\mathrm{H}, 4.87$. Found: $\mathrm{C}, 54.29 ; \mathrm{H}$, 4.84.

4.2.2.10. 7-(Benzo[d][1,3]dioxol-5-yl)-1,1,1,2,2-pentafluoroheptan-3-one (6j). Yield 67\%; Yellow oil; ${ }^{1} \mathrm{H}$ NMR $(200 \mathrm{MHz}$, $\left.\mathrm{CDCl}_{3}\right): \delta 6.90-6.50(\mathrm{~m}, 3 \mathrm{H}$, arom $), 5.92\left(\mathrm{~s}, 2 \mathrm{H}, \mathrm{OCH}_{2} \mathrm{O}\right), 2.78(\mathrm{t}$, $\left.2 \mathrm{H}, \mathrm{CH}_{2}, J=5.8 \mathrm{~Hz}\right), 2.57\left(\mathrm{t}, 2 \mathrm{H}, \mathrm{CH}_{2}, J=7.0 \mathrm{~Hz}\right), 1.85-1.50(\mathrm{~m}, 4 \mathrm{H}$, $\left.\mathrm{CH}_{2}\right) ;{ }^{13} \mathrm{C}$ NMR $\left(50 \mathrm{MHz}, \mathrm{CDCl}_{3}\right): \delta 194.2(\mathrm{t}, \mathrm{CO}, J=26 \mathrm{~Hz}), 147.6$, 145.7, 135.4, 121.0, $117.8\left(\mathrm{qt}, \mathrm{CF}_{3}, J_{1}=285 \mathrm{~Hz}, J_{2}=34 \mathrm{~Hz}\right.$ ), 108.7, 106.9 (tq, $\left.\mathrm{CF}_{2}, J_{1}=265 \mathrm{~Hz}, J_{2}=38 \mathrm{~Hz}\right), 100.8,37.1,35.2,30.6$, 21.7; ${ }^{19} \mathrm{~F} \mathrm{NMR}\left(188 \mathrm{MHz}, \mathrm{CDCl}_{3}\right): \delta-82.4\left(\mathrm{CF}_{3}\right),-123.8\left(\mathrm{CF}_{2}\right)$; $\mathrm{MS}$ (ESI) $m / z(\%): 323.2\left([\mathrm{M}+\mathrm{H}]^{+}, 100\right)$; Anal. Calcd for $\mathrm{C}_{15} \mathrm{H}_{15} \mathrm{~F}_{5} \mathrm{O}_{2}: \mathrm{C}$, 55.90; H, 4.69. Found: C, 55.98; H, 4.65.

4.2.2.11. 5-(Biphenyl-2-yl)-1,1,1,2,2-pentafluoropentan-3-one (13). Yield 48\%; Yellowish oil; ${ }^{1} \mathrm{H}$ NMR $\left(200 \mathrm{MHz}, \mathrm{CDCl}_{3}\right): \delta$ 7.70-7.10 (m, 9H, arom), 3.03 (t, $2 \mathrm{H}, \mathrm{CH}_{2}, J=7.0 \mathrm{~Hz}$ ), 2.85 (t, $2 \mathrm{H}$, $\left.\mathrm{CH}_{2}, J=7.0 \mathrm{~Hz}\right) ;{ }^{13} \mathrm{C}$ NMR $\left(50 \mathrm{MHz}, \mathrm{CDCl}_{3}\right): \delta 193.4(\mathrm{t}, \mathrm{CO}$, $J=26 \mathrm{~Hz}), 142.0,141.1,136.6,130.4,129.1,128.9,128.4,126.7$, $117.7\left(\mathrm{qt}, \mathrm{CF}_{3}, J_{1}=285 \mathrm{~Hz}, J_{2}=34 \mathrm{~Hz}\right), 106.8\left(\mathrm{tq}, \mathrm{CF}_{2}, J_{1}=265 \mathrm{~Hz}\right.$, $\left.J_{2}=38 \mathrm{~Hz}\right), 38.4\left(\mathrm{CH}_{2}\right), 26.0\left(\mathrm{CH}_{2}\right) ;{ }^{19} \mathrm{~F} \mathrm{NMR}\left(188 \mathrm{MHz}, \mathrm{CDCl}_{3}\right): \delta$ $-82.4\left(\mathrm{CF}_{3}\right),-123.9\left(\mathrm{CF}_{2}\right)$; $\mathrm{MS}(\mathrm{ESI}) \mathrm{m} / z(\%)$ : $327.2\left([\mathrm{M}-\mathrm{H}]^{-}\right.$,
100); Anal. Calcd for $\mathrm{C}_{17} \mathrm{H}_{13} \mathrm{~F}_{5} \mathrm{O}$ : $\mathrm{C}, 62.20 ; \mathrm{H}, 3.99$. Found: $\mathrm{C}$ 62.29; H, 3.95.

\subsubsection{1,1,1,2,2,3,3-Heptafluoro-8-(naphthalen-1-yl)octan-4-one} (7a)

The synthesis of heptafluoropropyl ketone 7a was carried out following the procedure described above for trifluoromethyl ketones, except that heptafluorobutanoic anhydride was used instead of trifluoroacetic anhydride. The product was purified by flash column chromatography [EtOAc-petroleum ether (bp $40-60{ }^{\circ} \mathrm{C}$ ) $5 /$ 95]. Yield 54\%; Yellow low mp solid; mp 31-32 ${ }^{\circ} \mathrm{C} ;{ }^{1} \mathrm{H}$ NMR $\left(200 \mathrm{MHz}, \mathrm{CDCl}_{3}\right): \delta 8.06-7.33\left(\mathrm{~m}, 7 \mathrm{H}\right.$, arom), $3.14\left(\mathrm{t}, 2 \mathrm{H}, \mathrm{CH}_{2}\right.$ $J=7.2 \mathrm{~Hz}), 2.82\left(\mathrm{t}, 2 \mathrm{H}, \mathrm{CH}_{2}, J=7.0 \mathrm{~Hz}\right), 1.86-1.80\left(\mathrm{~m}, 4 \mathrm{H}, \mathrm{CH}_{2}\right)$; ${ }^{13} \mathrm{C}$ NMR $\left(50 \mathrm{MHz}, \mathrm{CDCl}_{3}\right): \delta 193.9(\mathrm{t}, \mathrm{CO}, J=26 \mathrm{~Hz}), 137.6,133.9$, $130.0-102.5\left(\mathrm{~m}, \mathrm{CF}_{2}, \mathrm{CF}_{3}\right), 128.8,126.8,126.0,125.8,125.5$ 123.5, 37.8, 32.7, 29.6, 22.4; ${ }^{19} \mathrm{~F}$ NMR (188 MHz, $\left.\mathrm{CDCl}_{3}\right): \delta-81.05$ $\left(\mathrm{CF}_{3}\right),-121.56\left(\mathrm{CF}_{2}\right),-127.08\left(\mathrm{CF}_{2}\right) ; \mathrm{MS}(\mathrm{ESI}) \mathrm{m} / \mathrm{z}(\%): 379.1$ $\left([\mathrm{M}-\mathrm{H}]^{-}, 100\right)$; Anal. Calcd for $\mathrm{C}_{18} \mathrm{H}_{15} \mathrm{~F}_{7} \mathrm{O}: \mathrm{C}, 56.85 ; \mathrm{H}, 3.98$. Found: C, 56.72; H, 4.03.

\subsubsection{Synthesis of difluoromethyl ketones}

To a stirring mixture of magnesium ( $24 \mathrm{mg}, 1 \mathrm{mmol}$ ) and iodine in dry $\mathrm{Et}_{2} \mathrm{O}(1 \mathrm{~mL})$, a solution of bromide $14 \mathbf{a}$ or $\mathbf{1 4 b}(1 \mathrm{mmol})$ in dry $\mathrm{Et}_{2} \mathrm{O}(9 \mathrm{~mL})$ was added dropwise under $\mathrm{N}_{2}$ atmosphere. Once the Grignard reagent was formed, it was added dropwise to a cooled $\left(-78^{\circ} \mathrm{C}\right)$ solution of ethyl difluoroacetate $(62 \mathrm{mg}, 0.5 \mathrm{mmol})$ in dry ether $(0.5 \mathrm{~mL})$. The reaction mixture was stirred at $-78^{\circ} \mathrm{C}$ for $45 \mathrm{~min}$ and then was quenched with $1 \mathrm{~N} \mathrm{HCl}$. The aqueous layer was extracted with ether $(3 \times 25 \mathrm{~mL})$ and the combined organic layers were washed with brine, dried $\left(\mathrm{Na}_{2} \mathrm{SO}_{4}\right)$ and the solvent was evaporated in vacuo. The product was purified by flash column chromatography [EtOAc-petroleum ether (bp 40-60 ${ }^{\circ} \mathrm{C}$ ) 5/95].

4.2.4.1. 1,1-Difluoro-5-phenylpentan-2-one (16a). Yield 56\%; Colorless oil; ${ }^{1} \mathrm{H}$ NMR (200 MHz, $\left.\mathrm{CDCl}_{3}\right): \delta 7.40-7.10(\mathrm{~m}$, $5 \mathrm{H}, \mathrm{CH}), 5.66\left(\mathrm{t}, 1 \mathrm{H}, \mathrm{CHF}_{2}, J=54.0 \mathrm{~Hz}\right), 2.77-2.55\left(\mathrm{~m}, 4 \mathrm{H}, \mathrm{CH}_{2}\right)$, 1.99 (quintet, $2 \mathrm{H}, \mathrm{CH}_{2}, J=8.0 \mathrm{~Hz}$ ); ${ }^{13} \mathrm{C} \mathrm{NMR}\left(50 \mathrm{MHz}, \mathrm{CDCl}_{3}\right): \delta$ $199.6(\mathrm{t}, \mathrm{CO}, J=26.0 \mathrm{~Hz}), 140.9,128.5,128.4,126.1,109.8$ (d, $\left.\mathrm{CHF}_{2}, J=250 \mathrm{~Hz}\right), 35.2,34.7,23.8 ;{ }^{19} \mathrm{~F} \mathrm{NMR}\left(188 \mathrm{MHz}, \mathrm{CDCl}_{3}\right): \delta$ $-127.4\left(\mathrm{~d}, \mathrm{CHF}_{2}, J=54.5 \mathrm{~Hz}\right.$ ); MS (ESI) $\mathrm{m} / z(\%): 197.1\left([\mathrm{M}-\mathrm{H}]^{-}\right.$, 100); Anal. Calcd for $\mathrm{C}_{11} \mathrm{H}_{12} \mathrm{~F}_{2} \mathrm{O}$ : $\mathrm{C}, 66.66 ; \mathrm{H}, 6.10$. Found: $\mathrm{C}$, 66.78; H, 6.06 .

\subsubsection{1,1-Difluoro-6-phenylhexan-2-one $(16 b)^{45}$}

Yield 45\%; Colorless oil; ${ }^{1} \mathrm{H}$ NMR $\left(200 \mathrm{MHz}, \mathrm{CDCl}_{3}\right): \delta 7.37-7.07$ $(\mathrm{m}, 5 \mathrm{H}, \mathrm{CH}), 5.66\left(\mathrm{t}, 1 \mathrm{H}, \mathrm{CHF}_{2}, J=54 \mathrm{~Hz}\right), 2.78-2.52\left(\mathrm{~m}, 4 \mathrm{H}, \mathrm{CH}_{2}\right)$, 1.81-1.58 (m, 4H, $\left.\mathrm{CH}_{2}\right) ;{ }^{13} \mathrm{C}$ NMR $\left(50 \mathrm{MHz}, \mathrm{CDCl}_{3}\right): \delta 199.7(\mathrm{t}, \mathrm{CO}$ $J=26 \mathrm{~Hz}), 140.2,128.3,125.8,109.8\left(\mathrm{~d}, \mathrm{CHF}_{2}, J=251 \mathrm{~Hz}\right), 35.8$, 35.5, 30.6, 21.9; ${ }^{19} \mathrm{~F}$ NMR $\left(188 \mathrm{MHz}, \mathrm{CDCl}_{3}\right): \delta-127.4\left(\mathrm{~d}, \mathrm{CHF}_{2}\right.$, $J=54.5 \mathrm{~Hz}$ ); MS (ESI) $\mathrm{m} / z$ (\%): $211.2\left([\mathrm{M}-\mathrm{H}]^{-}, 100\right)$; Anal. Calcd for $\mathrm{C}_{12} \mathrm{H}_{14} \mathrm{~F}_{2} \mathrm{O}$ : C, 67.91; $\mathrm{H}, 6.65$. Found: C, 67.82; $\mathrm{H}, 6.69$.

4.3. In vitro PLA $A_{2}$ assays. The activity of $\mathrm{CPLA}_{2}, \mathrm{iPLA}_{2}$ and sPLA $_{2}$ were determined using modified Dole Assay. ${ }^{40-42}$ The buffer and substrate conditions were optimized for each enzyme assay as follows: (i) GIVA CPLA ${ }_{2}$ substrate mixed-micelles were composed of $400 \mu \mathrm{M}$ Triton X-100, $97 \mu \mathrm{M}$ PAPC, $1.8 \mu \mathrm{M}{ }^{14} \mathrm{C}$-labeled PAPC, and $3 \mu \mathrm{M} \mathrm{PIP}$ in $100 \mathrm{mM}$ HEPES buffer, pH 7.5, with $90 \mu \mathrm{M} \mathrm{CaCl}_{2}$, $2 \mathrm{mM}$ DTT, and $0.1 \mathrm{mg} / \mathrm{ml} \mathrm{BSA}$; (ii) GVIA iPLA 2 substrate mixed-micelles were composed of $400 \mu \mathrm{M}$ Triton X-100, $98.3 \mu \mathrm{M}$ PAPC, and $1.7 \mu \mathrm{M}{ }^{14} \mathrm{C}$-labeled PAPC in buffer containing $100 \mathrm{mM}$ HEPES, $\mathrm{pH}$ 7.5, $2 \mathrm{mM}$ ATP, and $4 \mathrm{mM}$ DTT; (iii) GV sPLA 2 substrate mixed-micelles were composed of $400 \mu \mathrm{M}$ Triton X-100, 98.3 $\mu \mathrm{M}$ PAPC, and $1.7 \mu \mathrm{M}{ }^{14} \mathrm{C}$-labeled PAPC in buffer containing 50 mMTris, pH 8.0, and $5 \mathrm{mM} \mathrm{CaCl}_{2}$. 
Initial screening of compounds at 0.091 mole fraction inhibitor in mixed-micelles was carried out. Compounds displaying $25 \%$ or less inhibition of the assays were considered to have no inhibitory affect (designated N.D.). We report average percent inhibition for compounds displaying less than $95 \%$ enzyme inhibition. If the percent inhibition was greater than $95 \%$, we determined its $X_{\mathrm{I}}(50)$ by plotting percent inhibition versus inhibitor mole fraction (typically 7 concentrations between 0.00091 and 0.091 mole fraction). Inhibition curves were modeled in Graphpad Prism 5.0 using nonlinear regression targeted at symmetrical sigmoidal curves based on plots of \% inhibition versus log (inhibitor concentration), to calculate the reported $X_{\mathrm{I}}(50)$ and associated error values.

\section{Acknowledgments}

This work was supported by the European Social Fund and National Resources Herakleitos II (A.S.) and by NIH Grant GM20501 (E.A.D.).

\section{Supplementary data}

Supplementary data (the synthesis and characterization data of all the intermediates) associated with this article can be found, in the online version, at http://dx.doi.org/10.1016/j.bmc.2013. 07.010 .

\section{References and notes}

1. Burke, J. E.; Dennis, E. A. Cardiovasc. Drugs Ther. 2009, 23, 45.

2. Dennis, E. A.; Cao, J.; Hsu, Y.-H.; Magrioti, V.; Kokotos, G. Chem. Rev. 2011, 111, 6130.

3. Ghosh, M.; Tucker, D. E.; Burchett, S. A.; Leslie, C. C. Prog. Lipid Res. 2006, 45, 487.

4. Clark, J. D.; Lin, L. L.; Kriz, R. W.; Ramesha, C. S.; Sultzman, L. A.; Lin, A. Y.; Milona, N.; Knopf, J. L. Cell 1991, 65, 1043.

5. Kramer, R. M.; Roberts, E. F.; Manetta, J.; Putnam, J. E. J. Biol. Chem. 1991, 266 5268.

6. Mounier, C. M.; Ghomashchi, F.; Lindsay, M. R.; James, S.; Singer, A. G.; Parton, R. G.; Gelb, M. H. J. Biol. Chem. 2004, 279, 25024.

7. Satake, Y.; Diaz, B. L.; Balestrieri, B.; Lam, B. K.; Kanaoka, Y.; Grusby, M. J.; Arm, J. P. J. Biol. Chem. 2004, 279, 16488.

8. Shirai, Y.; Balsinde, J.; Dennis, E. A. Biochim. Biophys. Acta 2005, 1735, 119.

9. Ackermann, E. J.; Kempner, E. S.; Dennis, E. A. J. Biol. Chem. 1994, 269, 9227.

10. Tang, J.; Kriz, R. W.; Wolfman, N.; Shaffer, M.; Seehra, J.; Jones, S. S. J. Biol. Chem. 1997, 272, 8567.

11. Balboa, M. A.; Balsinde, J.; Jones, S. S.; Dennis, E. A. J. Biol. Chem. 1997, 272, 8576.

12. Sedgwick, S. G.; Smerdon, S. J. Trends Biochem. Sci. 1999, 24, 311.
13. Balsinde, J.; Bianco, I. D.; Ackermann, E. J.; Conde-Frieboes, K.; Dennis, E. A. Proc. Natl. Acad. Sci. U.S.A. 1995, 92, 8527.

14. Balsinde, J.; Balboa, M. A.; Dennis, E. A. J. Biol. Chem. 1997, 272, 29317.

15. Balsinde, J.; Dennis, E. A. J. Biol. Chem. 1997, 272, 16069.

16. Ramanadham, S.; Hsu, F. F.; Bohrer, A.; Ma, Z.; Turk, J. J. Biol. Chem. 1999, 274, 13915.

17. Birbes, H.; Drevet, S.; Pageaux, J. F.; Lagarde, M.; Laugier, C. Eur. J. Biochem. 2000, 267, 7118 .

18. Ma, Z.; Bohrer, A.; Wohltmann, M.; Ramanadham, S.; Hsu, F. F.; Turk, J. Lipids 2001, 36, 689 .

19. Ma, Z.; Ramanadham, S.; Wohltmann, M.; Bohrer, A.; Hsu, F. F.; Turk, J. J. Biol. Chem. 2001, 276, 13198.

20. Balsinde, J.; Balboa, M. A. Cell. Signalling 2005, 17, 1052.

21. Balsinde, J.; Perez, R.; Balboa, M. A. Biochim. Biophys. Acta 2006, 1761, 1344.

22. Zachman, D. K.; Chicco, A. J.; McCune, S. A.; Murphy, R. C.; Moore, R. L.; Sparagna, G. C. J. Lipid Res. 2010, 51, 525.

23. Lei, X.; Barbour, S. E.; Ramanadham, S. Biochimie 2010, 92, 627.

24. Hooks, S. B.; Cummings, B. S. Biochem. Pharmacol. 2008, 76, 1059.

25. Wilkins, W. P.; Barbour, S. E. Curr. Drug Targets 2008, 9, 683.

26. Jenkins, C. M.; Cedars, A.; Gross, R. W. Cardiovasc. Res. 2009, 82, 240

27. Cao, J.; Burke, J. E.; Dennis, E. A. J. Biol. Chem. 2013, 288, 1806.

28. Magrioti, V.; Kokotos, G. Anti-Inflammatory Anti-Allergy Agents Med. Chem. 2006, 5, 189.

29. Magrioti, V.; Kokotos, G. Expert Opin. Ther. Pat. 2010, 20, 1.

30. Magrioti, V.; Kokotos, G. Expert Opin. Ther. Pat. 2013, 23, 333.

31. Ackermann, E. J.; Conde-Frieboes, K.; Dennis, E. A. J. Biol. Chem. 1995, 270, 445

32. Conde-Frieboes, K.; Reynolds, L. J.; Lio, Y.; Hale, M.; Wasserman, H. H.; Dennis, E. A. J. Am. Chem. Soc. 1996, 118, 5519.

33. Lio, Y. C.; Reynolds, L. J.; Balsinde, J.; Dennis, E. A. Biochim. Biophys. Acta 1996, 1302, 55.

34. Hsu, Y.-H.; Dumlao, D. S.; Cao, J.; Dennis, E. A. PLoS One 2013, 8, e59267.

35. Song, H.; Ramanadham, S.; Bao, S.; Hsu, F.-F.; Turk, J. Biochemistry 2006, 45, 1061.

36. Baskakis, C.; Magrioti, V.; Cotton, N.; Stephens, D.; Constantinou-Kokotou, V.; Dennis, E. A.; Kokotos, G. J. Med. Chem. 2008, 51, 8027.

37. Kokotos, G.; Hsu, Y. H.; Burke, J. E.; Baskakis, C.; Kokotos, C. G.; Magrioti, V.; Dennis, E. A. J. Med. Chem. 2010, 53, 3602.

38. Kalyvas, A.; Baskakis, C.; Magrioti, V.; Constantinou-Kokotou, V.; Stephens, D.; Lpez-Vales, R.; Lu, J. Q.; Yong, V. W.; Dennis, E. A.; Kokotos, G.; David, S. Brain 2009, 132, 1221.

39. Hsu, Y.-H.; Bucher, D.; Cao, J.; Li, S.; Yang, S.-W.; Kokotos, G.; Woods, V. L.; McCammon, J. A.; Dennis, E. A. J. Am. Chem. Soc. 2013, 135, 1330.

40. Stephens, D.; Barbayianni, E.; Constantinou-Kokotou, V.; Peristeraki, A.; Six, D. A.; Cooper, J.; Harkewicz, R.; Deems, R. A.; Dennis, E. A.; Kokotos, G. J. Med. Chem. 2006, 49, 2821.

41. Six, D. A.; Barbayianni, E.; Loukas, V.; Constantinou-Kokotou, V.; HadjipavlouLitina, D.; Stephens, D.; Wong, A. C.; Magrioti, V.; Moutevelis-Minakakis, P.; Baker, S.; Dennis, E. A.; Kokotos, G. J. Med. Chem. 2007, 50, 4222.

42. Kokotos, G.; Six, D. A.; Loukas, V.; Smith, T.; Constantinou-Kokotou, V.; Hadjipavlou-Litina, D.; Kotsovolou, S.; Chiou, A.; Beltzner, C. C.; Dennis, E. A. J. Med. Chem. 2004, 47, 3615.

43. Makriyannis, A.; Nikas, S. P.; Alapafuja, S. O.; Shukla, V. G. WO Patent 2008/ 013963 A2.

44. Makriyannis, A.; Nikas, S. P.; Alapafuja, S. O.; Shukla, V. G. WO Patent 2009/ 052319 A1.

45. Ichikawa, J.; Sonoda, T.; Kobayashi, H. Tetrahedron Lett. 1989, 30, 5437. 